\title{
Intraoral Foregut Cystic Developmental Malformations

\author{
Three cases with a brief review of literature
}

Arti Khatri,, "Lavleen Singh, ${ }^{1}$ Neha Jain, ${ }^{2}$ Mamta Sengar, ${ }^{3}$ Abhijit Das ${ }^{1}$

$$
\text { تشوهات نمائية كيسية معوية أمامية داخل الفم }
$$

$$
\text { أرتي كاتري، لفلين سنج، نيها جيان، مامتا سينجر، أبهيجت داس }
$$

ABSTRACT: Foregut cystic developmental malformations (FCDM) are a type of rare cystic lesion. The occurrence of FCDM is exceedingly uncommon in the intraoral location. We report three cases of FCDM with intraoral location who presented at Chacha Nehru Bal Chikitsalaya, New Delhi, India, in 2016, 2017 and 2018 with symptoms of respiratory distress and feeding difficulties. Two patients were male and one was female with an age range of 29 days to eight years. The clinical differential diagnosis included mucocele, ranula, dermoid, lymphangioma, teratoma, thyroglossal duct cyst, etc. All patients were treated with simple surgical excision and diagnosed, based on histopathology, with FCDM. These should be considered as differential diagnosis of head and neck midline cystic mass lesions. This case report aimed to discuss differential diagnosis and appropriate terminology for these cystic masses as there is varied and ambiguous nomenclature.

Keywords: Bronchogenic Cyst; Cyst; Congenital Abnormalities; Oral Cavity; Case Report; India.

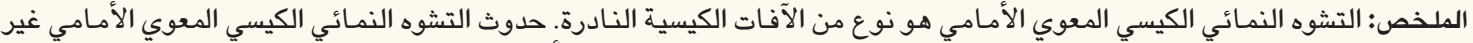

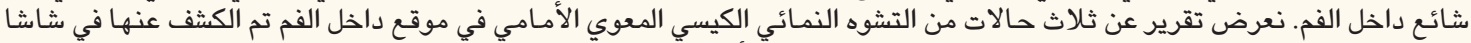

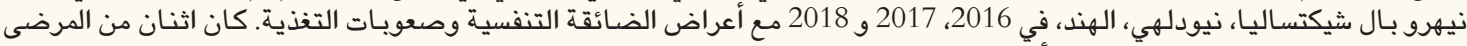

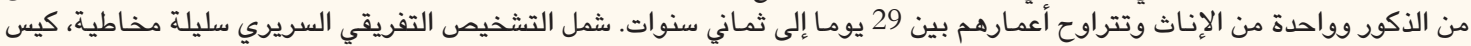

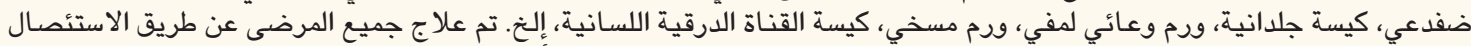

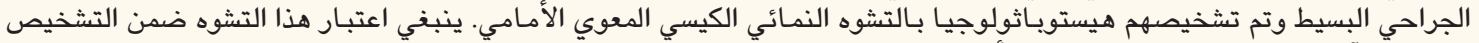

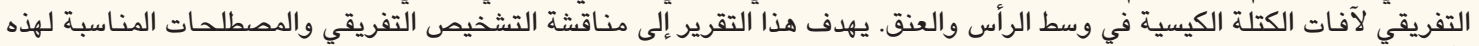

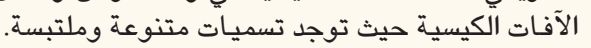

$$
\begin{aligned}
& \text { الكلمات المفتاحية: كيسة قصبية المنشأ؛ كيس؛ التشوهات الخلقية؛ جوف الفم؛ تقرير حالة؛ الهند. }
\end{aligned}
$$

$\mathrm{F}$ OREGUT CYSTIC DEVELOPMENTAL MALFORmations (FCDM) are a type of choristomas containing histologically normal gastrointestinal and respiratory epithelium. These arise due to migration anomalies during fetal life. ${ }^{1}$ The most common site for FCDM are the chest and abdomen and can occur anywhere along the alimentary tract. However, the oral cavity is one of the rarest locations. Most cases present in the neonatal period with a cystic mass lesion in the head and neck, causing difficulty in breathing or deglutition. The common differential diagnosis of paediatric cystic head and neck masses includes dermoid, lymphangioma, venous malformation, haemangioma, teratoma, thyroglossal duct cyst and lymphoepithelial cyst. ${ }^{2}$ FCDM is an exceedingly rare cause of a midline cystic mass lesion in the head and neck, especially in an intraoral location. FCDM have a risk of malignant transformation such as adenocarcinoma if left untreated. ${ }^{3}$ We present three cases of intraoral FCDM with one case of anterior involvement of the tongue and two involving the floor of the mouth. These cases highlight the rarity of these developmental lesions and stress the need for uniform nomenclature to establish better communication between histopathologists and surgeons. Informed consent was given by the legal guardians of all patients.

\section{Case One}

A 29-day-old male infant presented to Chacha Nehru Bal Chikitsalaya, New Delhi, India, in 2018 with a cystic swelling measuring $3 \times 2 \mathrm{~cm}$ located in the anterior ventral surface of the tongue causing feeding difficulty [Figure 1A]. The swelling was present at birth and gradually increased in size which resulted in posterior displacement of the tongue causing difficulty 

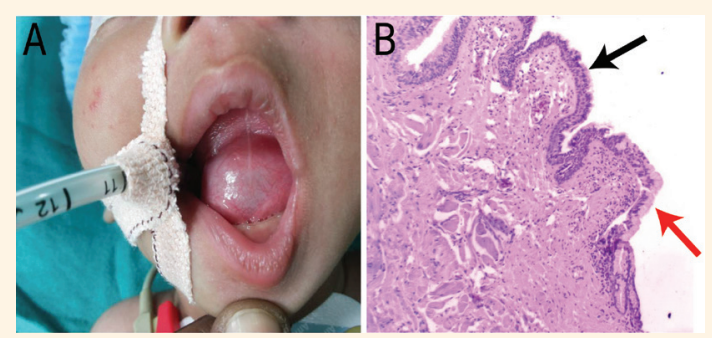

Figure 1: A: Intraoperative photograph of a 29-day-old male infant showing cystic swelling in the ventral surface of the anterior tongue. B: Haematoxylin and eosin stain of the cystic swelling tissue sample at x100 magnification showing a cyst wall lined with pseudostratified ciliated columnar epithelium (black arrow) and gastric epithelium (red arrow) with a smooth muscle layer beneath.

during feeding. There were no associated anomalies. Laboratory tests including complete blood count, liver function tests, renal function tests and coagulation profile were within normal limits.

Ultrasonography of the floor of mouth showed a cystic swelling measuring $5 \times 4 \mathrm{~cm}$ in the midline, pushing on the muscles of the floor of the mouth. The cyst was completely resected and tissue was sent for histopathological examination with a provisional diagnosis of a ranula. The patient was discharged one day postoperatively. Follow-ups during the next six months were uneventful.

On gross inspection, the cyst was well circumscribed measuring a maximum of $3 \mathrm{~cm}$ in diameter and containing a mucinous transparent fluid. Histopathological examination revealed a fibromuscular wall partially lined by ciliated pseudostratified columnar epithelium and gastric epithelium. Few mucinous glands were seen embedded within the wall. Based on these findings, the patient was diagnosed with a lingual FCDM [Figure 1B].

\section{Case Two}

An eight-month-old female infant presented at Chacha Nehru Bal Chikitsalaya in 2017 with swelling in the floor of the mouth with complaints of respiratory distress. On local examination, a non-transilluminant swelling was present in the floor of the mouth extending up to the base of the tongue measuring $3.5 \times 2.5 \mathrm{~cm}$ [Figure $2 \mathrm{~A}$ ]. Provisional clinical diagnoses were infected ranula and epidermoid cyst. There were no associated anomalies. The patient did not undergo preoperative radiological investigation and the swelling was excised and sent for histopathological examination. On gross examination, it was a soft, cystic swelling, greyish white in colour with the smooth outer surface. The cut section showed a multiloculated cyst with the presence of turbid fluid. Microscopic examination showed a cyst wall with

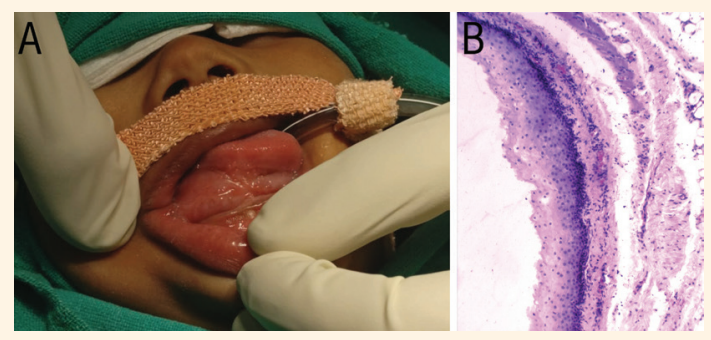

Figure 2: A: Intraoperative photograph of an eightmonth-old female infant showing cystic swelling in the floor of the mouth. B: Haematoxylin and eosin stain of the cystic swelling tissue sample at x100 magnification showing a cyst wall lined by stratified squamous epithelium and a smooth layer beneath it.

a smooth muscle layer lined by stratified squamous and overlying pseudostratified columnar epithelium [Figure 2B]. The surrounding fibro-fatty soft tissue and skeletal muscle showed mild inflammation. Subsequently, the patient was diagnosed with intraoral FCDM. The postoperative follow-up period of one year was uneventful.

\section{Case Three}

An eight-year-old boy presented to the outpatient department of Chacha Nehru Bal Chikitsalaya in 2016 with a small anterior neck swelling. The swelling had been present for one year. On local physical examination, the swelling was firm in consistency and located in the anterior floor of the mouth. It appeared to be an enlarged submental lymph node. A provisional clinical diagnosis of tubercular lymphadenitis was made and fine needle aspiration was attempted but did not yield any diagnostic material. Laboratory tests including complete blood count, liver function test, renal function test and coagulation profile were within normal limits. The patient did not undergo any preoperative radiological investigation and the swelling was excised and sent for histopathological examination. On gross examination, it was a single globular cystic soft tissue piece measuring $1 \times 0.5 \times 0.5 \mathrm{~cm}$. Microscopic examination showed a cyst wall with smooth muscle layer lined by pseudostratified ciliated columnar epithelium. Mild chronic inflammation was noted in the surrounding tissue. The final diagnosis of FCDM was based on clinical and histopathological findings. The postoperative follow-up period of one year was uneventful.

\section{Discussion}

FCDM are rare congenital choristomas which develop due to aberrant embryogenesis. ${ }^{1,3}$ They can occur 


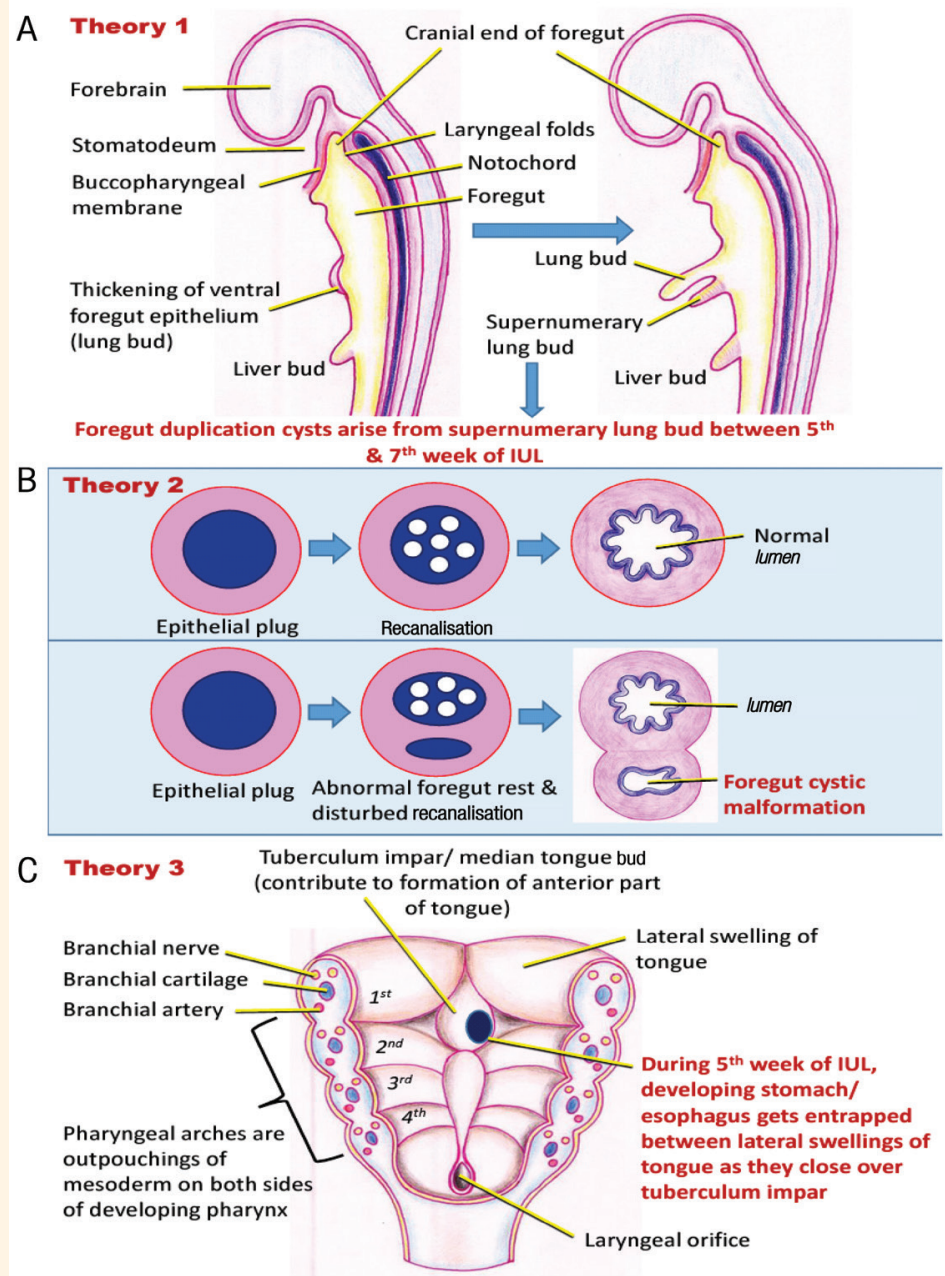

Figure 3: Pictures of theories explaining the formation of foregut cystic developmental malformations (FCDM). A: Theory one depicts foregut duplication cysts arising from supernumerary lung bud. B: Theory two shows the normal canalisation of foregut epithelial plug during intrauterine life which leads to the formation of a normal lumen. Disturbed recanalisation may lead to the formation of an abnormal heterotopic rest in relation to the developing gut wall, which may later result in cystic developmental malformations. C: Theory three shows that during embryogenesis the developing stomach may become entrapped between lateral lingual swellings explaining the occasional presence of gastric epithelium in oral FCDM.

IUL = intrauterine life.

anywhere from the mouth to anus but the most common site for FCDM is the chest and abdomen. ${ }^{3}$ Approximately one-third of total alimentary tract duplication cysts are foregut duplication cysts and the noted incidence of alimentary tract duplication is $1: 4500 .^{4}$ Oral cavity FCDM comprises $0.3 \%$ of all alimentary tract duplications. In addition, the anterior part of the tongue is one of the rarest sites for FCDM. ${ }^{1}$

Congenital gastric and intestinal cysts of the oral cavity are mostly solitary with a male preponderance. Clinical features of the FCDM depend on the location, size and type of epithelial lining. Oral FCDM may present with feeding and breathing difficulties or manifest in unexpected ways such as recurrent bleeding. ${ }^{5}$ These may be complicated by obstruction, perforation or infection with the continued growth of these cystic masses if not surgically removed. ${ }^{6}$
The first case of FCDM was reported by Duncan and Daniel in 1942.7 Various authors have used different terminologies such as oral cyst with heterotopic gastrointestinal mucosa, congenital gastrointestinal cyst, gastrointestinal duplication cyst, enteric duplication cyst, foregut cyst, epithelial cyst, cyst of foregut origin, cystic duplication, etc.; this creates and adds to the confusion amongst histopathologists and paediatric surgeons regarding its nomenclature. Sharma et al. proposed that, as these malformations share their origin from the foregut and are cystic, they should be labelled as FCDM. ${ }^{8}$ There are various theories of the formation of FCDM. The most widely accepted theory for the formation of FCDM is that during the third week of embryogenesis, foregut division is followed by the formation of diverticula (normal lung bud) from the ventral part of foregut; the 
formation of an additional diverticula (supernumerary lung bud) may occur as a result of aberration in normal embryogenesis. During the fifth and seventh week of embryogenesis, a foregut duplication cyst develops from this supernumerary lung bud which explains the presence of respiratory type epithelium in FCDM [Figure 3A] ${ }^{3,8}$ Another theory says that the disturbed recanalisation of the foregut during intrauterine life leads to the development of abnormal foregut rests in relation to the wall of the developing gut, leading to formation of FCDM from these rests. The cyst lining of FCDM depends on the epithelial type of these heterotopic rests [Figure 3B]. ${ }^{9}$ When these heterotopic rests are incorporated into a hollow structure such as the gastrointestinal tract it leads to duplication of the muscle layer; these are also known as a duplication cyst. The presence of two layers of smooth muscle indicates an attempt at recapitulating the outer and inner muscle coat of intestine. ${ }^{8}$ Gorlin and Jirasek and, later, Daley et al. proposed that the entrapment of stomach or stomatodeum between lateral swellings of the tongue during the embryonic period as they close over the tuberculum impar can result in presence of heterotopic gastric mucosa in FCDM [Figure 3C]., ${ }^{9,10}$ Foregut duplication cyst is frequently associated with vertebral anomalies; Veeneklaas proposed that the abnormal persistence of foregut adherence to notochord is responsible for this association. ${ }^{11}$

FCDM are benign anomalies which need to meet three diagnostic criteria: (1) a smooth muscle layer; (2) covering epithelium derived from the foregut; and (3) attachment to a part of the foregut. ${ }^{4}$ These cysts may show squamous metaplasia, mucosal ulceration, inflammation and necrosis and therefore pose a diagnostic challenge. ${ }^{3}$

FCDM should be considered as differential diagnosis of other midline developmental cystic lesions in the head and neck region. The differential diagnosis for midline cystic lesions of the oral cavity include mucocele, dermoid cyst, lymphoepithelial cyst, thyroglossal duct cyst, etc. ${ }^{2,13}$ The overlapping clinical and radiological features of midline cystic mass lesions in the head and neck necessitates a histopathological confirmation for appropriate management of these lesions. ${ }^{12}$

Mucocele is the most appropriate clinical differential diagnosis for intraoral FCDM as it has similar clinical characteristics and radiological features. ${ }^{13}$ The management of mucocele includes removal of the fibrous capsule along with the associated minor salivary gland. In addition, on clinical and imaging findings it is difficult to distinguish FCDM from dermoid cysts, thyroglossal duct cysts and lymphoepithelial cysts. While simple surgical excision is curative in FCDM, dermoid and lymphoepithelial cysts, a Sistrunk operation is required for thyroglossal duct cysts. Antenatal ultrasonography can be a useful investigation for antenatal diagnosis of FCDM. If antenatal ultrasonography shows findings suggestive of FCDM ex utero intrapartum management of these lesions should be started to prevent respiratory compromise. In an emergency situation when a child presents with respiratory compromise, the cyst should be aspirated to relieve obstruction with excision of the cyst to be done at a later date. ${ }^{13,14}$

Surgical excision is the treatment of choice as there is an increased risk of malignancy in untreated cases. $^{1,15}$

\section{Conclusion}

Intraoral FCDM commonly presents with difficulty in breathing and deglutition. This should be considered in the differential diagnosis of other developmental midline cystic lesions in the head and neck region. A uniform embryology-based nomenclature of developmental anomalies, such as FCDM, should be used to avoid confusion between histopathologists and paediatric surgeons. In addition, antenatal ultrasonography may aid in early diagnosis and timely management.

\section{References}

1. Patel P, Branstetter BF 4th, Myers EN. Lingual foregut duplication in a middle-aged adult. AJNR Am J Neuroradiol 2011; 32:E40-1. https://doi.org/10.3174/ajnr.A1994.

2. Vogl TJ, Stegler W, Ihrler S, Ferrera P, Grevers G. Cystic masses in the floor of the mouth: Value of MR imaging in planning surgery. AJR Am J Roentgenol 1993; 161:183-6. https://doi. org/10.2214/ajr.161.1.8517299.

3. Kieran SM, Robson CD, Nosé V, Rahbar R. Foregut duplication cysts in the head and neck: Presentation, diagnosis, and management. Arch Otolaryngol Head Neck Surg 2010; 136:778-82. https://doi.org/10.1001/archoto.2010.127.

4. Qi BQ, Beasley SW, Williams AK. Evidence of a common pathogenesis for foregut duplications and esophageal atresia with tracheo-esophageal fistula. Anat Rec 2001; 264:93-100. https://doi.org/10.1002/ar.1125.

5. Mir R, Weitz J, Evans J, Coren C. Oral congenital cystic choriostomas: A case report. Pediatr Pathol 1992; 12:835-8. https:// doi.org/10.3109/15513819209024240.

6. Burgner DP, Carachi R, Beattie TJ. Foregut duplication cyst presenting as neonatal respiratory distress and haemoptysis. Thorax 1994; 49:287-8. https://doi.org/10.1136/thx.49.3.287.

7. Duncan GW, Daniel RA, Jr. Cystic tumor of the tongue: Report of an unusual case. Arch Surg 1942; 44:164-9. http://doi.org/10.1 001/archsurg.1942.01210190167018.

8. Sharma S, Nezakatgoo N, Sreenivasan P, Vanatta J, Jabbour N. Foregut cystic developmental malformation: New taxonomy and classification--unifying embryopathological concepts. Indian J Pathol Microbiol 2009; 52:461-72. https://doi.org/10.4103/03 77-4929.56119. 
9. Daley TD, Wysocki GP, Lovas GL, Smout MS. Heterotopic gastric cyst of oral cavity. Head Neck Surg 1984; 7:168-71. https://doi.org/10.1002/hed.2890070212.

10. Gorlin RJ, Jirasek JE. Oral cysts containing gastric or intestinal mucosa. An unusual embryological accident or heterotopia. Arch Otolaryngol 1970; 91:594-7. https://doi.org/10.1001/ archotol.1970.00770040824018.

11. Veeneklaas GM. Pathogenesis of intrathoracic gastrogenic cysts AMA Am J Dis Child 1952; 83:500-7. https://doi.org/10.1001/ archpedi.1952.02040080096010.

12. Stocker JT, Dehner LP, Husain AN. Stocker \& Dehner's Pediatric Pathology. 4th ed. Philadelphia, USA: Wolters Kluwer, 2016.
13. Chen MK, Gross E, Lobe TE. Perinatal management of enteric duplication cysts of the tongue. Am J Perinatol 1997; 14:161-3. https://doi.org/10.1055/s-2007-994119.

14. Kong K, Walker P, Cassey J, O'Callaghan S. Foregut duplication cyst arising in the floor of mouth. Int J Pediatr Otorhinolaryngol 2004; 68:827-30. https://doi.org/10.1016/j.ijporl.2004.01.011.

15. Agaimy A, Raab B, Bonkowsky V, Wünsch PH. Intestinal-type adenocarcinoma arising in a congenital sublingual teratoid cyst. Virchows Arch 2007; 450:479-81. https://doi.org/10.1007/s004 28-007-0369-8. 